\title{
AC 2011-1477: DEVELOPMENT OF AN UNDERGRADUATE RESEARCH LABORATORY
}

\section{Adrian Ieta, Oswego State University College}

Adrian Ieta (M'99) received the B.Sc. degree in physics from the University of Timisoara, Timisoara, Romania, in 1984, the B.E.Sc. degree in electrical engineering from the "Politehnica" University of Timisoara, Timisoara, in 1992, and the M.E.Sc. degree and the Ph.D. degree in electrical and computer engineering from The University of the Western Ontario, London, ON, Canada, in 1999 and 2004, respectively. He was with the Applied Electrostatics Research Centre and the Digital Electronics Research Group, The University of Western Ontario, where he worked on industrial projects and taught. He is currently an Assistant Professor in the Department of Physics, State University of New York at Oswego. Dr. Ieta is a member of Professional Engineers of Ontario.

\section{Rachid Manseur, State University of New York at Oswego}

Rachid Manseur is currently the Director of Engineering Development and a member of the Computer Science faculty at SUNY Oswego where he is actively developing a new modern and innovative Electrical and Computer Engineering Program. His academic interests lie in Engineering Education and Engineering Program Development, Robotics, Visualization and Simulation Software Development, and Digital and Embedded System Design. He holds a Ph.D in Electrical Engineering from the University of Florida, an MS degree in EE from the University of Houston, and a licence-es-sciences in Mathematics from the University of Algiers. He is registered as a professional Engineer in the State of Florida and the author of numerous articles in his areas of expertise including the textbook "Robot Modeling and Kinematics" and its associated modeling and visualization software.

\section{Dr. Thomas E. Doyle P.Eng., McMaster University}




\section{DEVELOPMENT OF AN UNDERGRADUATE RESEARCH LABORATORY}

We report our experience in setting up a research laboratory at a non-PhD granting institution. The intention was to create an applied electrostatics lab with the potential to become research competitive in the field after a few years of development. In the initial stages we started with a modest budget and a small lab space. However, upon very careful equipment selection and research on sources, the lab's capabilities became a reality. Undergraduate students working in the lab in the initial stages were of utmost importance in its development. Some of the purchased devices were improved to allow for more versatile usage. The first lab results in the field of electrosprays were obtained, analyzed, presented and published within the first year of the lab's development. These initial successes led to more student participation in the lab resulting in increased experimental setups, measurements and analysis conducted in the subsequent year. Micro and nano particle production and analysis are now available in the lab. With help from colleagues, old equipment was adapted for the study of electrosprays in reduced pressure or vacuum. New interesting results were obtained and a research course will be offered next semester that will rely on this laboratory as a primary platform. The research capabilities, after two and a half years, include electrospray and electrospinning, high speed imaging of droplets, micro and nanoparticle generation, thin films deposition, ferro-fluids, and gas discharge studies. With the development of a new science and engineering building complex, a unique opportunity to design the lab space for research became available. While the development of the lab started on a small institutional grant, proposals for future funding have been submitted to national agencies. The successful experience in lab development discussed in this article can be of interest to other instructors with similar targets.

\section{INTRODUCTION}

Laboratory activity is essential for student success and preparation for industry, research, and real-life work [1,2]. Setting up a new lab or improving the ones in place [2-4] is always a challenging task. Laboratory development is often one of the important tasks assigned to new faculty, who normally have good research experience but have not yet acted on their own to manage funds, select suppliers, make purchases and set up a competitive lab. There are many approaches and innovative ideas to accomplish such a task [5,6]. While some lab development can be supported by substantial grants [7-9], things can easily become very disappointing when startup funds are unavailable to support the faculty's research plans. The task of setting up a lab may often be vital, as research results in the lab and publications can provide additional grant proposal ideas for external funding, which can promote new research at higher levels. Nevertheless, solutions can sometimes be found $[1,6,10]$. This article discusses the plan and the decisions made in designing and setting up a new undergraduate research lab. 


\section{BACKGROUND}

State University of New York at Oswego is developing a new undergraduate program in electrical and computer engineering (ECE) to better serve its communities and to meet the workforce needs of the area. The development of a new program presents an opportunity to create a modern and innovative curriculum that challenges several aspects of traditional engineering education and responds to the needs of the knowledge-based society we live in. A new faculty member was hired (Fall 2008), temporarily based in the Physics department. Although more money will be available for equipment and laboratory at the actual start of the ECE program (a few years later), there was little startup money $(\$ 12,000)$ at the time of the hiring. Although an additional \$5,000 was offered from a different source the total amount remained modest for setting up a competitive research lab. This is likely to be the case with many small departments and non-PhD granting universities. The allocated lab space was also relatively small. The reasoning and choices that were made in order to overcome these financial constraints are presented here.

\section{Reasoning for money allocation}

The first major decision was related to the nature of the lab:

What are the main types of experiments to be conducted in the near future and will those have relevance in the following years?

Previously, research in the field of gas discharges/plasma and applied electrostatics was conducted. However, it was felt that due to the tremendous potential of nanotechnology, this field of research would be long-lasting, with many applications in various fields. One of the avenues to nanotechnology, but also many other applications, is electrospraying, a method for liquid atomization. When high voltage is applied to a conductive capillary containing a polar fluid, an electrospray can be generated. Charge droplets emitted at the tip of Taylor's cone undergo coulombic fissions as they move towards the counter electrode. There are various regimes in which the electrospray can be operated [11-12] but the most widely used in research is the stable cone-jet regime [13] which is particularly useful in mass spectrometry [14-16]. Other important electrospray applications include drug delivery [17], drug micro-encapsulation [18], production of nanofibers, thin film deposition [19, 20] and fine particle production [21]. The method was well researched lately, but due to the complexity of the processes created it is not completely understood; many applications (from fundamental research to industry) of electrospray appear every year. To produce an electrospray, one essentially needs a high voltage

power supply, a readily available device at low prices. Controlling the electrospray by various means is key to many of its applications and electrical engineers play a vital role in this task. 
Therefore, a research lab devoted to electrosprays offers an excellent platform for applied research involving undergraduate electrical engineering students. However, one would like to have alternatives instead of a one-way direction for research, even if very promising. A multipurpose lab would be desirable. Given that high voltage power supplies can also be used for gas discharges, a new broad direction for research is also available. In addition, the study of ferrofluids is possible in a small lab. There is particular interest in new magneto-optic effects that can be achieved using ferromagnetic fluids. Moreover, one Physics faculty is a specialist in magnetism and adequate equipment is readily available in this direction.

After consulting the literature, former colleagues and supervisors, inquiring about products at different companies, the following list of desirable equipment, with indicated prices as of the time of inquiry, was established:

- two high voltage power supplies (one positive and one negative polarity) $(\$ 7-10,000)$

- $\quad+/-10 \mathrm{kV}$ high voltage amplifier $(\$ 9-14,000)$

- high speed camera and lighting system $(+\$ 20,000)$

- syringe pump $(\$ 3-5,000)$

- electrometer $(\$ 3-5,000)$

- four channel oscilloscope

- signal generator

- syringes and needles

- tubing and other supplies

The next significant question to answer was:

\section{What are the purchasing options?}

A quick examination of the above list shows that the startup funds were certainly insufficient for the goal. Local resources were important. An oscilloscope, signal generator, and multimeters were available and provided by the department. However, working with a tight budget can still be productive, provided that various avenues are correctly evaluated. It should be noted that many times new and fancy equipment does not necessarily bring in more value than older equipment in working condition. Many times most of the advanced features of the new purchased equipment remain completely unused. Therefore, the first thought was to look at suppliers of used power supplies. The price dropped from about $\$ 5,000$ to about $\$ 1,800$. However, more in-depth search led to finding such items also available on eBay at even lower prices ( $\$ 500$ or less). The risk/reward factor was attractive ( $\$ 5,000$ new/ $\$ 500$ used). Additional research was needed about the eBay sellers. They were contacted directly regarding details on the state of the equipment and return policies. In the bidding process, synchronization with the atomic clock and calibrated the response time were used for bidding. This process ensured great success in getting the items needed. Three power supplies $(+/-3 \mathrm{kV}$ precision power supply 
$\$ 320,-10 \mathrm{kV}-\$ 500$, and $+40 \mathrm{kV}-\$ 500)$ were purchased. The units were bought one at a time and verified to be in good working condition. The $-10 \mathrm{kV}$ power supply needed to be modified to work on the $220 \mathrm{~V}$ input voltage available in the lab. In addition, one single syringe pump and one double syringe pump as well as other minor items deemed necessary were also bought at a fraction of the cost of new ones and are in good working condition. The high voltage amplifier was purchased new, with an educational discount. In addition, negotiations with two firms brought the price somehow lower than it would have been otherwise. A used high speed camera was acquired for less than half of its quoted price. This acquisition process clearly shows that some old-style bargaining methods become necessary when development funds are scarce.

\section{Additional help with lab development}

One of the students interested in research was very instrumental in lab development. The first steps taken in setting up the lab were to ensure proper grounds for the power supplies, high speed camera and other equipment in the proximity of the high voltage area. In addition, some financial help was received from the department, and a proposal was submitted for an institutional grant. The grant paid for two students to work in the lab. Another internal grant was awarded at a later time and it helped with the progress of the research efforts. Three NSF collaborative grants were also submitted (one still pending) and more are planned for submission.

A machine shop is available and has been of great help in manufacturing items needed for different experimental setups. Two undergraduate students working in the shop are shown on Figure 1. They are modifying adaptors for the syringe pumps in order to make them more versatile in working with high voltage.

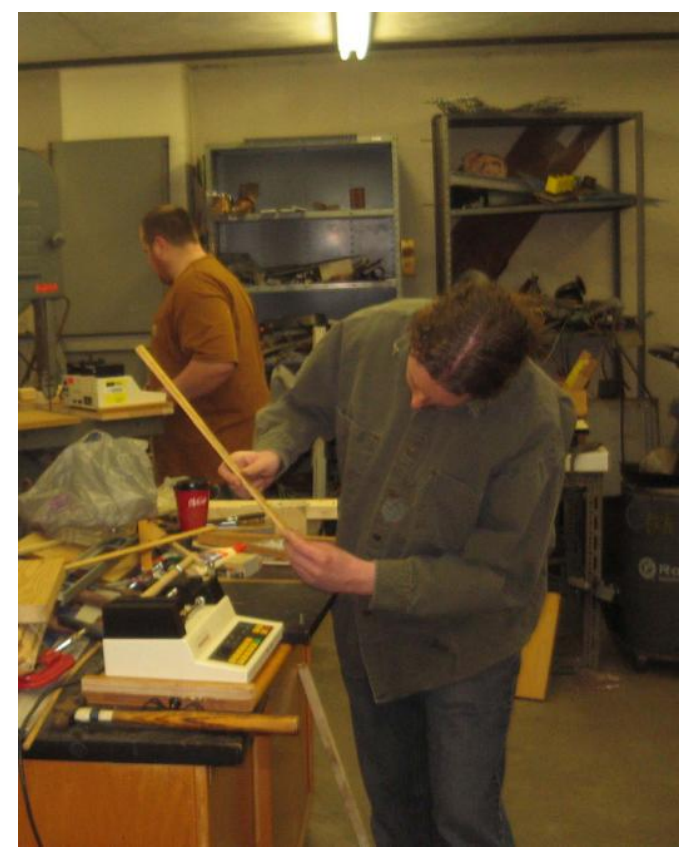

Fig.1 Two undergraduate students in the shop making adjustments to the purchased equipment. 


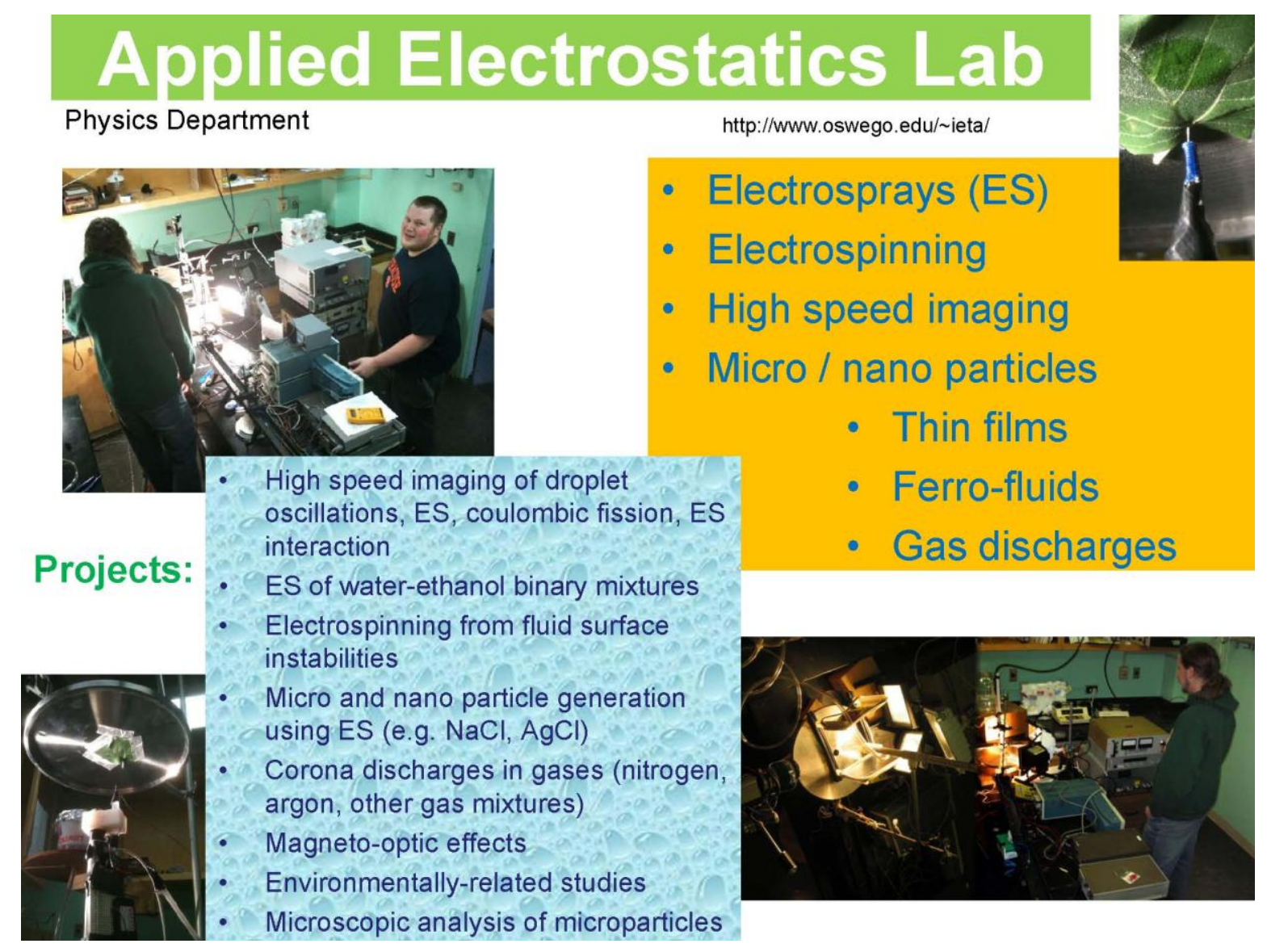

Fig.2 Lab flyer designed for presentations

Figure 2 shows a laboratory description and advertisement flyer for the electrostatic lab used on the institution web site.

Substantial help with various issues was received from the lab assistants in the Physics and Chemistry departments. Access to optical microscopes was obtained from the Biology Department and at our institution's Rice Creek Field Station. The microscopes allow examination of the micro-particulates locally, while SEM analysis for nanoparticulates is available from another nearby university.

It is well known that undergraduate research is very different from research done with graduate students. The undergraduates have their course work as a priority and there is usually little time left for coherent research work. Nevertheless, during the first year, several accomplishments were achieved including collection of experimental data, performance analyses, research and presentations at local and international conferences. So far, four undergraduates and one highschool student have worked in the lab and contributed to its development. At present, two articles have been published based on lab data and research results were presented at a few conferences and published in their proceedings. Two students were awarded third place for the best student presentation at an international conference in the summer of 2010. Other 
presentations related to the lab and its capabilities were also conducted. A flyer used for this purpose is shown in Fig 2.

Figure 3 shows images related to microparticle synthesis by electrospray and ferromagnetic fluids experiments (Fig. 3). Collaborative work with an international research center has been initiated last year.

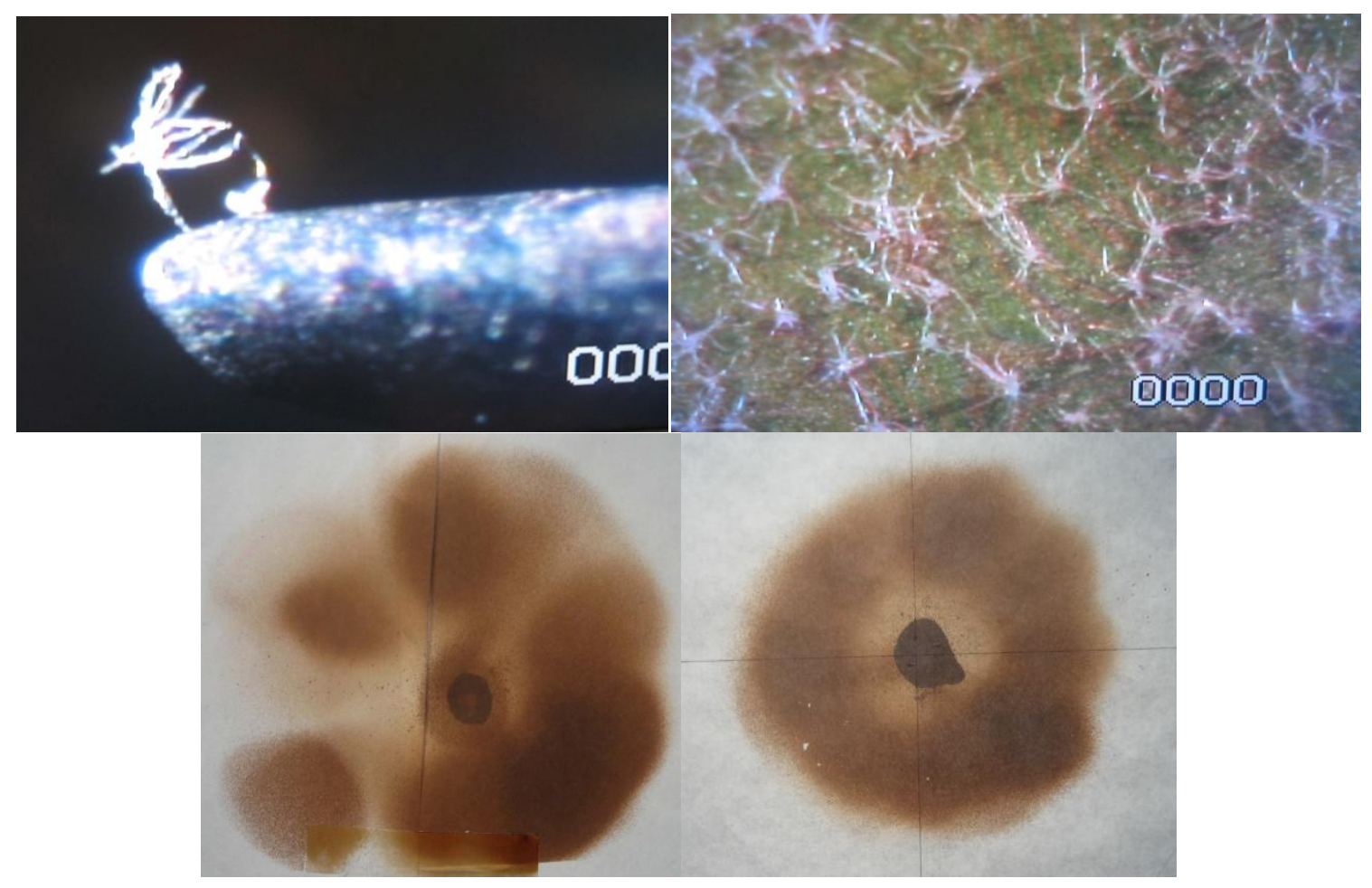

Fig. 3 Some interesting results from the lab work related to microparticle generation and ferrofluid experiments.

\section{LATEST DEVELOPMENTS}

An old VEECO instrument, **** Add sentence on what a VEECO instrument is **** has been located in the department and made available. With the help of a senior faculty, the instrument is installed in the laboratory and allows the study of electrospray at reduced atmospheric pressure. The instrument is still being adjusted for this purpose but it is estimated that the procedure will be completed during Spring 2011. These changes will allow for quicker evaporation of the spray droplets and essentially open up a different avenue for micro and nano-particle synthesis. One of the authors will teach a capstone course in the Spring that will use the developed laboratory as the main research facility. Students will collaborate in their research, working in groups or individually on different projects within the lab's capabilities. 


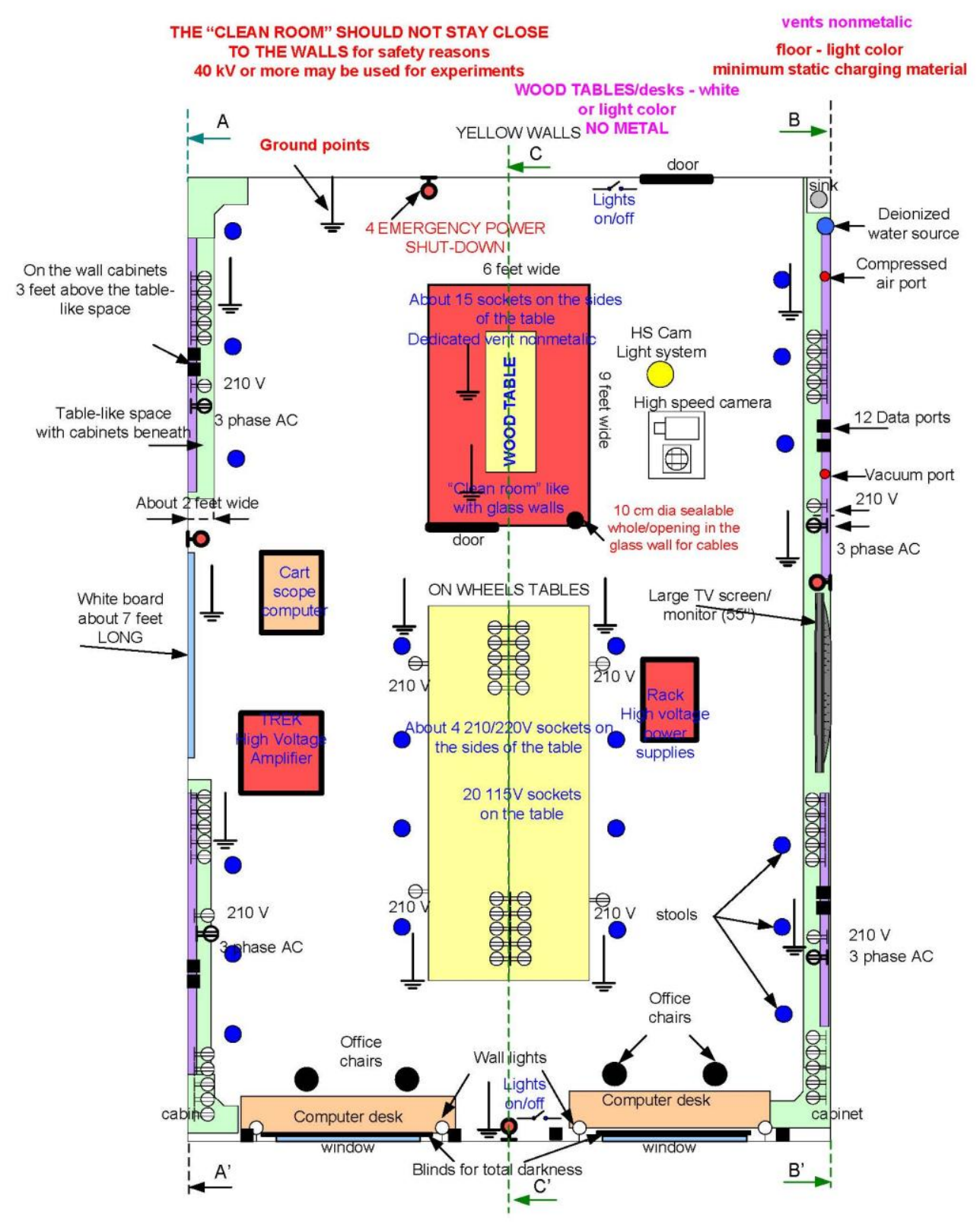

Fig. 4 Sketch of the new laboratory space in the new Arts and Sciences building.

\section{NEW LABORATORY LOCATION}

A new $\$ 180 \mathrm{M}$ Science and Engineering building is currently under construction in our campus. The ECE program, conceived to be competitive within the engineering education field, will be located in the new building. This provided a unique opportunity to design both classrooms and laboratories according to our vision of an active-learning approach to engineering education and modern laboratories. A sketch of the future research laboratory facility is given in Fig. 4. 
The sketch has been slightly modified by the builders but it will preserve all the main features suggested in the drawing. In designing the new lab space, available options for building the actual room were exploited. Safety features were taken in consideration related to the use of high voltage and of the substances manipulated or synthesized, and to the possibility of acquiring equipment that works on different input voltages. A major principle was again the multifunctionality of laboratory space. The building and the laboratory are scheduled to be completed in Fall 2013.

\section{CONCLUSIONS}

This article describes the successful development of a laboratory for faculty and undergraduate student research on several areas related to electrosprays. Development work was successful in spite of the many difficulties one can encounter in such an endeavor. Each step in lab development presents different challenges. Economical ways for finding solutions are discussed. Fund limitations can be solved to a certain extent by examining local resources such as departmental help, internal grants, locally used equipment and expertise or external grants, industry partnerships, or business donors. A detailed examination of the actual lab needs may reveal that used equipment is essentially as good as new one for research objectives. Used equipment reduces acquisition costs to a fraction of catalog prices. New faculty would particularly benefit from collaborations, pivotal for success. In addition, introducing undergraduates to research early will put them on track quickly; they will have ideas of their own, which may further enhance laboratory work and capabilities. Most colleagues are ready to help in various ways, which benefits the developer and may also help build long-lasting relations of collegiality and friendship. The lab development efforts discussed in this article demonstrate that modest initial funds can be sufficient for the development of a viable and vibrant undergraduate research lab, productive in teaching, research, and publications. This article provides an example of lab development at a public undergraduate institution that may be useful to other faculty and other institution in their quest to develop laboratories to support their work as well as engage undergraduate students in research.

\section{REFERENCES}

[1] Farrow, D., and R. LeMaster. "Automation laboratory development enhances student learning." Proceedings of the ASEE Annual Conference \& Exposition, Chicago, IL, June 18-21, 2006.

[2] Scott, S., R. Athinarayanan, Xiaobing Hou, and Shuju Wu. "Integrated curriculum and laboratory development of an undergraduate telecommunications and computer networking program." Proceedings of the ASEE Annual Conference \& Exposition, Pittsburgh, PA, June 22$25,2008$. 
[3] Li, Shuhui. "Laboratory development and restructuring for the course of electric drives or energy conversion using software and hardware IT tools." Proceedings of the ASEE Annual Conference \& Exposition, Portland, OR, June 12-15, 2005.

[4] Zion, G. "Laboratory development for a VHDL Design Course." Proceedings of the ASEE Annual Conference \& Exposition, session 3647, Montreal, Canada, June 15-19, 2002.

[5] Jung, Yong-Kyu. "A new rapid microprocessor system design laboratory development for digital design education." Proceedings of the ASEE Annual Conference \& Exposition, Chicago, IL, June 18-21, 2006.

[6] Alvarado, J., and M. Golla. "A successful collaboration model for educators and industry partners for laboratory development and enhancement." Proceedings of the ASEE Annual Conference \& Exposition, Austin, TX, June 14-17, 2009.

[7] McDonald, D. and P. Duesing. "Laboratory development in power generation, conversion, and dissipation." Proceedings of the ASEE Annual Conference \& Exposition, Salt Lake City, Utah, 2004.

[8] Furman, B. J., F. Barez, J. C. Wang, P. Hsu, P. Reischl, and T. R. Hsu. "Mechatronics Engineering laboratory development at San Jose State University." Proceedings of the ASEE Annual Conference \& Exposition, Milwaukee, WI, June 15-18, 1997.

[9] Rosato, A. D., Ian S. Fischer, Jonathan Luke, Rajesh N. Dave, Robert Pfeffer, and Doris Yacoub. "On laboratory development for a Curriculum in Particle Technology." Proceedings of the ASEE Annual Conference \& Exposition, Milwaukee, WI, June 15-18, 1997.

[10] Hutzel, William J. "Leveraging Campus Resources for HVAC laboratory development." Proceedings of the ASEE Annual Conference \& Exposition, St. Louis, MO, June 2000.

[11] Juraschek, R., and F. W. Rollgen. "Pulsation phenomena during electrospray ionization." International Journal of Mass Spectrometry 177.1 (3 August 1998): 1-15.

[12] Jaworek, A., and A. Krupa. "Classification of the modes of EHD spraying." Journal of Aerosol Science 30.7 (August 1999): 873-893.

[13] Cloupeau M, and B. Prunetfoch. "Electrostatic spraying of liquids in cone-jet mode." Journal of electrostatics 22.2 (1989): 135-159.

[14] Gomez, A., and K. Q. Tang. "Charge and fission of droplets in electrostatic sprays." Physics of Fluids 6.1 (1994): 404-14.

[15] Manisali, Irina, David D. Y. Chen, and Bradley B. Schneider. "Electrospray ionization source geometry for mass spectrometry: past, present, and future." Trends in Analytical Chemistry 25.3 (2006): 243-56.

[16] Fenn, John B. "Electrospray wings for molecular elephants (Nobel Lecture)." Angew. Chem. Int. Ed. 42 (2003): 3871-94.

[17] Chakraborty, Syandan, I-Chien Liao, Andrew Adler, and Kam W. Leong. "Electrohydrodynamics: A facile technique to fabricate drug delivery systems." Advanced drug delivery reviews 61.12 (2009): 1043-1054.

[18] Loscertales, I. G., A. Barrero, I. Guerrero, R. Cortijo, M. Marquez, and A. M. Ganan-Calvo. "Micro/nano encapsutation via electrified coaxial liquid jets." Science 295.5560 (2002): 16951698.

[19] Jaworek, A. "Electrospray droplet sources for thin film deposition." Journal of Materials Science 42.1 (2007): 266-297.

[20] Salata, O. V. "Tools of Nanotechnology: Electrospray." Current Nanoscience 1.1 (2005): 25-33. 
[21] Jaworek, A. "Micro- and nanoparticle production by electrospraying." Powder Technology 176 (2007): 18-35.

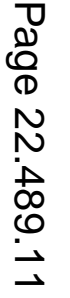

